\title{
Cadernos dos Alunos
}





\section{Cyberbullying na visão dos alunos de Iniciação Científica do Projeto Pixel do Colégio de Aplicação da UFRGS: um estudo de caso}

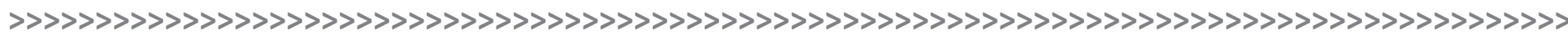

Hevelyn Fayette Benites*

Victor Hugo Nedel Oliveira**

\section{Resumo:}

O Cyberbullying é uma forma de intimidação cada vez mais presente no cotidiano de jovens e adolescentes contemporâneos. Esta pesquisa teve como principal objetivo analisar as percepções dos alunos de iniciação científica do Projeto Pixel, turma 80 de língua francesa sobre o Cyberbullying. Para atingir os objetivos propostos, foi realizada uma entrevista com 8 estudantes do 8 o ano do ensino fundamental, do Projeto Pixel do Colégio de Aplicação da UFRGS sobre o tema de pesquisa. Os resultados de pesquisa apontaram que as redes sociais nos dias de hoje estão mais amplas e precisam de mais atenção, devemos cuidar mais o que acessamos, o que compartilhamos e o que curtimos. O índice de Cyberbullying é um problema sério que a sociedade enfrenta, e, que muitas pessoas ainda não fornecem a atenção e não tomam as medidas necessárias. É possível considerar que ainda falta muito para que a sociedade tenha a devida atenção ao tema do Cyberbullying.

\section{Palavras-chave:}

Cyberbullying. Alunos. Escola.

\section{Resumen:}

El Cyberbullying es una forma de intimidación que está cada vez más presente en la vida cotidiana de los jóvenes y adolescentes. El objetivo principal de esta investigación fue analizar las percepciones de los estudiantes de pregrado del Proyecto Pixel, clase de idioma francés 80 sobre el Cyberbullying. Para lograr los objetivos propuestos, se realizó una entrevista con 8 estudiantes del octavo grado de la escuela primaria, del Proyecto Pixel del Colégio de Aplicação de UFRGS sobre el tema de investigación. Los resultados de la investigación mostraron que las redes sociales actuales son más amplias y necesitan más atención, debemos cuidar mejor a qué accedemos, qué compartimos y qué disfrutamos. El acoso cibernético es un problema grave que enfrenta la sociedad, y muchas personas aún no prestan atención y no toman las medidas necesarias. Se puede considerar que hay un largo camino por recorrer antes de que la sociedad preste la atención al tema del Cyberbullying.

\section{Palabras-clave:}

Cyberbullying. Alumnos. Escuela.
* $>$ Estudante do 9 ano do Ensino Fundamental do Colégio de Aplicação da UFRGS. E-mail: heve.fayette@gmail.com.

** > Doutor em Educação, professor do Departamento de Humanidades do Colégio de Aplicação da Universidade Federal do Rio Grande do Sul (UFRGS). E-mail: victor.juventudes@gmail.com. 


\section{Introdução}

O assunto de pesquisa que escolhi realizar é sobre Cyberbullying, e, como recorte, escolhi o tema Cyberbullying na vida dos adolescentes no IC Pixel 80 Francês.

A minha pesquisa é sobre o Cyberbullying, e, eu quero mostrar para as pessoas o quão esse problema pode afetar os adolescentes da minha faixa etária.

A pergunta de pesquisa desta investigação foi: "Qual a percepção sobre o Cyberbullying dos alunos Pixel IC 80 Francês?" E as perguntas secundárias foram: "Porque o Cyberbullying existe?" e "Quais são as consequências do Cyberbullying na sociedade?"

Esta pesquisa é resultante do Projeto Pixel (http://www.ufrgs.br/projetopixel), do Colégio de Aplicação da UFRGS e, no oitavo ano, o tema central das investigações é "identidade", portanto, minha pesquisa relaciona-se com o tema, pois o Cyberbullying está presente na vida de várias pessoas, principalmente na minha faixa etária. Além disso, o Cyberbullying pode afetar em diversas formas uma pessoa, como por exemplo, o seu psicológico.

A justificativa desta investigação é que eu escolhi trabalhar sobre esse assunto pois eu vejo várias reportagens sobre o Cyberbullying e como esse problema está ficando mais comum entre adolescentes. Além disso, eu sempre me interessei em saber sobre esses assuntos que afetam a mente, e, que tem muita influência sobre a internet.

O que eu sabia, antes de realizar a investigação sobre o tema escolhido era: que esse assunto é bem delicado, então devemos ter cuidado ao falar dele; o Cyberbullying é um bullying que acontece virtualmente, com a intenção de prejudicar o outro.

O objetivo principal desta investigação foi analisar as percepções dos alunos do IC Pixel 80 Francês sobre o Cyberbullying.

\section{Revisão bibliográfica}

Para explorar o tema que escolhi para a pesquisa realizei dois movimentos: a leitura de livros selecionados na biblioteca do Colégio de Aplicação e a leitura de artigos científicos selecionados a partir de levantamento no Google Acadêmico.

\section{Biblioteca}

O primeiro livro que li intitulava-se Adolescentes seguros: como aumentar a autoestima dos jovens, escrito por Harris Clemes, Reynold Bean e Aminah Clark, no ano de 1995. Os principais aprendizados com este material foram: A autoestima origina-se de todas as experiências, ideias, sensações que reunimos a respeito de nós mesmos durante a vida. Todos nós precisamos ter uma boa autoestima independente de idade, sexo, formação cultural ou instrução e trabalho. Vários estudos psicológicos indicam que, enquanto a necessidade de autoestima não é satisfeita, o preenchimento de necessidades mais amplas — criatividade, conquistas, percepção do pleno potencial - é limitado.

O segundo livro que li intitulava-se Adolescer: estudos sobre adolescência, escrito por José Outeiral, no ano de 1994. Os principais aprendizados com este material foram: que os jovens modifiquem a sociedade e ensinem os adultos a ver o mundo em forma renovada: mas onde existe o desafio de um jovem em crescimento que haja um adulto para encará-lo. E não é obrigatório que isso seja agradável. A identidade de um alguém é formada a partir do momento em que a pessoa nasce, e desde então, vão se formando outros pontos importantes para que todos os pontos desenvolvam a sua própria identidade. 


\section{Artigos científicos}

O primeiro artigo científico que li intitulava-se Cyberbullying: outro tipo principal de bullying?, escrito por Robert Slonje e Peter Smith, publicado na revista Scandinavian: Journal of Psychology, no ano de 2008. Os principais aprendizados com este texto foram: o artigo falou sobre uma pesquisa com alunos suecos sobre o Cyberbullying no cotidiano. Diferenças de gênero eram poucas. O impacto do Cyberbullying foi percebido como altamente negativo para a imagem/videoclipe de bullying. Na maioria das vezes, os cibervictos preferem contar a seus amigos ou a ninguém sobre o Cyberbullying, então os adultos podem não estar cientes do Cyberbullying, e (além da imagem/vídeo clip bullying) é assim que foi percebido pelos alunos.

O segundo artigo científico que li intitulava-se Cyberbullying e auto-estima, escrito por Sameer Hinduja e Justin Patchin, publicado na revista Journal of School Health, no ano de 2010. Os principais aprendizados com este texto foram: este artigo examina a relação entre a experiência de alunos do ensino médio com o Cyberbullying e seu nível de autoestima. Pesquisas anteriores sobre o bullying tradicional entre adolescentes encontraram uma ligação relativamente consistente entre a vitimização e a baixa auto-estima, ao mesmo tempo em que encontraram uma relação inconsistente entre a ofensa e a baixa auto-estima.

O terceiro artigo científico que li intitulava-se Intimidação, Cyberbullying e suicídio, escrito por Sameer Hinduja e Justin Patchin, publicado na revista Archives of Suicide Research, no ano de 2010. Os principais aprendizados com este texto foram: estudos empíricos e alguns casos anedóticos de alto perfil demonstraram uma ligação entre ideação suicida e experiências com vitimização ou ofensa de bullying. O presente estudo examina até que ponto uma forma não tradicional de agressão entre pares - o Cyberbullying também está relacionada à ideação suicida entre adolescentes. Em 2007, uma amostra aleatória de 1.963 estudantes do ensino fundamental de um dos maiores distritos escolares dos Estados Unidos completou uma pesquisa sobre o uso e as experiências da Internet.

\section{Aprendizados com as referências}

As principais questões que aprendi com esses autores e utilizarei na minha pesquisa foram: o Cyberbullying é um problema muito sério, e, que às vezes não damos tanta atenção para esse assunto que está ficando cada vez mais presente na sociedade. As redes sociais têm grande influência sobre o Cyberbullying, pois ao mesmo que elas são legais, fazendo a gente ficar por dentro das notícias, modas, atualidades, elas também podem ser bem prejudiciais na vida de uma pessoa. O Cyberbullying não é apenas o comentário maldoso, o Cyberbullying já começa quando a pessoa compartilha alguma foto constrangedora de um colega; e quando os envolvidos são jovens e crianças, o problema piora.

\section{Metodologia}

O roteiro básico da pesquisa foi organizado da seguinte forma: definir tema; fazer a caracterização da entrevista; analisar as fontes; analisar as fontes metodológicas; realizar as entrevistas; analisar os resultados; e por fim, apresentar a pesquisa.

O tipo de pesquisa que escolhi realizar foi qualitativa, porque eu acredito que seja melhor coletar os dados por entrevistas, e, também porque o meu assunto é bem delicado para fazer questionários. O universo da investigação foi 16 alunos e a amostra (recorte) foi 8 pessoas. 
Utilizei, para a coleta de dados, o instrumento: entrevistas. A minha entrevista foi elaborada da seguinte forma:

» idade;

" gênero;

» etnia;

» onde mora;

»1) na sua opinião, o que é Cyberbullying?;

"2) por onde você ouviu falar sobre o Cyberbullying?;

»3) você acha importante saber sobre a gravidade do Cyberbullying? Por quê?;

"4) você acha importante que fale sobre o Cyberbullying na escola? Por quê?; e

" 5) que ações você acredita que deveriam ser usadas para evitar o Cyberbullying? Cite exemplos.

Para analisar as informações coletadas, realizei a análise do discurso das respostas dos entrevistados e montei gráficos.

\section{Resultados}

Os resultados da minha pesquisa foram divididos em duas etapas, a primeira apresentando a caracterização da amostra da pesquisa e a segunda parte apresentando e discutindo os dados coletados na investigação, a partir da interpretação da entrevista realizada.

\section{Amostra de pesquisa}

$\mathrm{Na}$ amostra de pesquisa, apresentarei os seguintes dados: idade, gênero, etnia e onde mora. Esta etapa é importante para podermos conhecer quem foram os entrevistados.

Idade

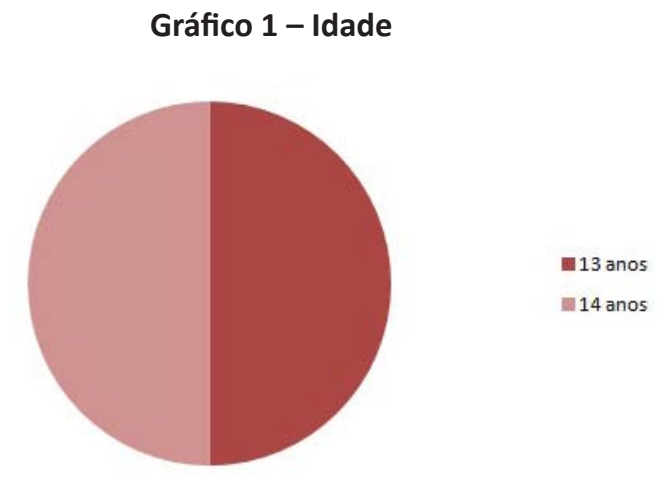

Fonte: Elaborado pelos autores (2019).

Da minha amostra de pesquisa pude constatar que 50\% tem 13 anos; 50\% tem 14 anos. Ou seja, a maioria da minha amostra de pesquisa encontra-se na faixa dos 13 aos 14 anos. 


\section{Gênero}

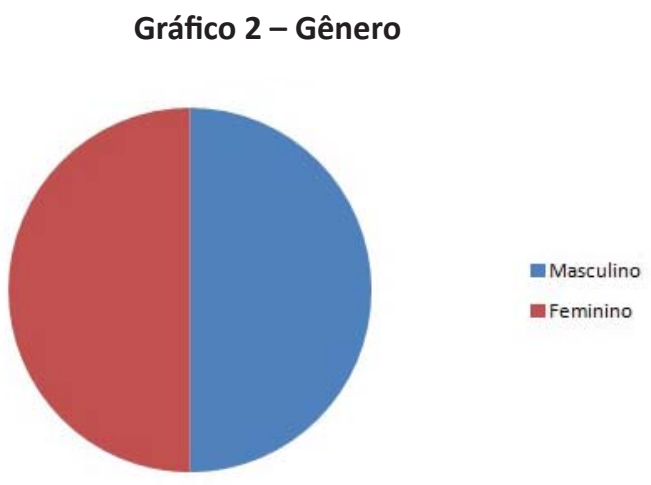

Fonte: Elaborado pelos autores (2019).

Da minha amostra de pesquisa pude constatar que 50\% são do gênero masculino, $50 \%$ são do sexo feminino e $0 \%$ preferiu não responder sobre a questão de gênero. Ou seja, a maioria da minha amostra de pesquisa identifica-se com os gêneros masculino e feminino.

\section{Etnia}

Gráfico 3 - Etnia

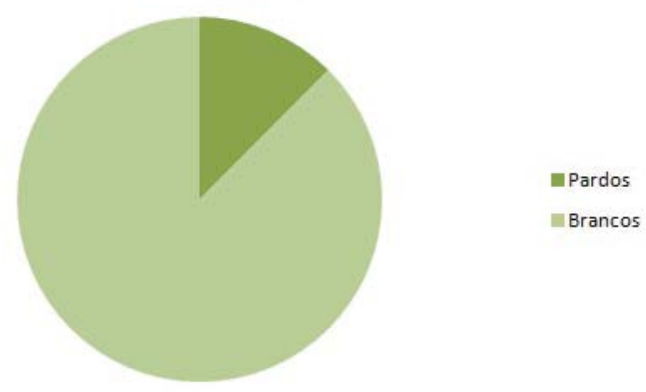

Fonte: Elaborado pelos autores (2019).

Da minha amostra de pesquisa pude constatar que $87,5 \%$ identificam-se como brancos, $0 \%$ identifica-se como negros, $12,5 \%$ identificam-se como pardos, $0 \%$ identifica-se como indígenas e $0 \%$ afirmaram identificar-se com outras etnias. Ou seja, a maioria da minha amostra de pesquisa identifica-se com a etnia branca.

\section{Onde mora}

Gráfico 4 - Onde mora

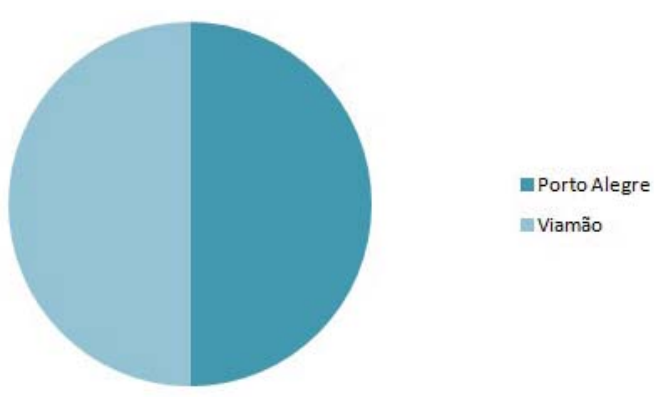

Fonte: Elaborado pelos autores (2019). 
Da minha amostra de pesquisa pude constatar que 50\% moram em Porto Alegre e 50\% moram em Viamão. Ou seja, a maioria da minha amostra de pesquisa mora em Porto Alegre e Viamão.

\section{Entrevista}

Pergunta 1: "Na sua opinião, o que é Cyberbullying?"

A minha pergunta 1 era "Na sua opinião, o que é Cyberbullying?". Escolhi essa pergunta, pois eu queria ver quais eram as diferentes opiniões sobre o conceito de Cyberbullying.

As respostas mais relevantes para a análise foram: "Cyberbullying é um bullying que ocorre virtualmente", "Cyberbullying são ofensas feitas pela internet" e "Cyberbullying é um abuso que acontece pelas plataformas digitais". Acredito que essas respostas foram apontadas pelos sujeitos da pesquisa pois é basicamente isso que falam pra gente na escola, muitas vezes a família também monta esse conceito na nossa cabeça e em algumas redes sociais sempre tem um pequeno momento de conscientização sobre o bullying, Cyberbullying, depressão e outros transtornos psicológicos que nos ajudam a pensar e a montar uma opinião.

Pergunta 2: "Por onde você ouviu falar sobre o Cyberbullying?"

A minha pergunta 2 era "Por onde você ouviu falar sobre o Cyberbullying?". Escolhi essa pergunta pois é importante saber por onde os alunos ouviram falar sobre o Cyberbullying.

As respostas mais relevantes para a análise foram: "A primeira vez que ouvi falar foi pela pesquisadora Hevelyn Fayette", "Por campanhas e notícias" e "Por uma série: SCI Cyber". Acredito que essas respostas foram apontadas pelos sujeitos da pesquisa pois o Cyberbullying está cada vez mais presente e faz com que a mídia produza mais conteúdo sobre isso.

Pergunta 3: "Você acha importante saber sobre a gravidade do Cyberbullying? Por quê??"

A minha pergunta 3 era "Você acha importante saber sobre a gravidade do Cyberbullying? Por quê?”. Escolhi essa pergunta pois é sempre importante saber se as pessoas se interessam em saber sobre a gravidade do Cyberbullying.

As respostas mais relevantes para a análise foram: "Sim, eu acredito que seja importante também para conscientizar mais as pessoas", "Sim, pois existem muitas pessoas que passam por isso e precisam de ajuda" e "Acredito que sim, pois na geração de hoje o índice de bullying é bem alto". Acredito que essas respostas foram apontadas pelos sujeitos da pesquisa pois todos já tem uma opinião um pouco mais formada e sabem que o Cyberbullying é muito grave e necessita de mais atenção.

Pergunta 4: "Você acha importante que fale sobre o Cyberbullying na escola?"

A minha pergunta 4 era "Você acha importante que fale sobre o Cyberbullying na escola?”. Escolhi essa pergunta pois eu gostaria de saber se os sujeitos entrevistados acham importante que fale sobre o Cyberbullying na escola.

As respostas mais relevantes para a análise foram: "Sim, pois as atividade virtuais serão cada vez mais frequentes", "Sim, pois isso acontece com adolescentes" e "Eu acho que sim, porém para falar sobre isso precisa de muito cuidado". Acredito que essas respostas foram apontadas pelos sujeitos da pesquisa pois eles sabem que esse assunto é delicado e que requer muita cautela na hora de debater sobre.

Pergunta 5: "Que ações você acredita que deveriam ser usadas para evitar o Cyberbullying? Cite exemplos" 
A minha pergunta 5 era "Que ações você acredita que deveriam ser usadas para evitar o Cyberbullying? Cite exemplos”. Escolhi essa pergunta pois eu gostaria de ver se os sujeitos entrevistados saberiam me dar exemplos de ações para evitar o Cyberbullying.

As respostas mais relevantes para a análise foram: "Conversar mais sobre esse assunto", "Supervisionar mais o que as crianças acessam na internet" e "Respeitar mais o outro". Acredito que essas respostas foram apontadas pelos sujeitos da pesquisa pois grande parte deles já entendem sobre as ações que devem ser praticadas para evitar o Cyberbullying.

\section{Considerações finais}

Assim como o projeto de pesquisa e a realização das etapas metodológicas são muito importantes, a chegada nas conclusões da pesquisa também é.

Assim, vou apresentar as considerações da minha pesquisa:

\section{Quanto às pesquisas bibliográficas (biblioteca e artigos no Google Acadêmico)}

Em todas as minhas referências bibliográficas eu procurei absorver o maior número de informações possíveis para acrescentar na minha pesquisa, como por exemplo: algumas informações de como ter uma boa autoestima é importante, sobre o jovem e sua identidade e o cuidado que devemos ter nas redes sociais.

\section{Quanto à aplicação do meu instrumento de pesquisa}

Com as entrevistas, eu aprendi várias coisas envolvendo ética, o tipo de pergunta que eu devo ou não fazer, e como eu devo me comportar na hora de fazer a entrevista.

\section{Aprendizados para além da investigação}

\section{Os meus principais aprendizados com essa pesquisa foram:}

O Cyberbullying é um assunto muito importante para se tratar, principalmente com jovens da minha faixa etária, que cada vez mais utilizam os recursos da internet. As redes sociais nos dias de hoje estão mais amplas e precisam de mais atenção, devemos cuidar mais o que acessamos, o que compartilhamos e o que curtimos. O índice de Cyberbullying é um problema sério que a sociedade enfrenta, e, que muitas pessoas ainda não fornecem a atenção e não tomam as medidas necessárias.

Os principais aprendizados, para além dos resultados, ou seja, o que eu aprendi para a vida nesta pesquisa foi:

Tomar mais cuidado com o que eu posto nas redes sociais e sempre respeitar as outras pessoas. 
Fazer pesquisa científica no colégio é importante, pois:

Nos ajuda a ter mais autonomia, nos traz mais conhecimentos, nos estimula a ter mais intimidade com os livros e também nos ajuda praticar mais a nossa comunicação.

\section{Referências}

CLEMES, Harris; BEAN, Reynold; CLARK, Aminah. Adolescentes seguros: como aumentar a autoestima dos jovens. São Paulo: Gente, 1995.

HINDUJA, Sameer; PATCHIN, Justin. Cyberbullying e auto-estima. Journal of School Health, Bloomington, v. 80, n. 12, p. 614-621, 2010a.

HINDUJA, Sameer; PATCHIN, Justin. Intimidação, Cyberbullying e suicídio. Archives of Suicide Research, London, v. 14, n. 3, p. 206-221, 2010b.

OUTEIRAL, José. Adolescer: estudos sobre adolescência. Porto Alegre: Artes Médicas, 1994.

SLONJE, Robert; SMITH, Peter. Cyberbullying: outro tipo principal de bullying? Scandinavian: Journal of Psychology, Linköping, v. 49, n. 2, p. 147-154, 2008. 